\title{
Pharmacogenetics of Cytochrome P450 2D6: A Translational Medicine Perspective
}

\author{
Imtiaz M. Shah*, Catherine J. Breslin, Kitiyaporn Wittayanarakul and Simon P. Mackay \\ Strathclyde Institute of Pharmacy and Biomedical Sciences, University of Strathclyde, Glasgow, Scotland, G4 ONR, UK
}

\begin{abstract}
With rapid scientific advances in the postgenomic era, pharmacogenomics has developed into an important area of translational medicine research. Pharmacogenetics studies the variability in drug response between different patient genotypes. By using patient genomic information, this bench-to-bedside research approach aims to develop more effective targeting of drug therapy in clinical practice. This will potentially reduce the risk of adverse drug reactions and avoid treatment failure. One of the important areas of pharmacogenetic variability is in drug metabolism via the cytochrome P450 (CYP) enzyme system. Cytochrome P450 2D6 (CYP2D6) metabolises up to 30\% of commonly used drugs but this enzyme displays extensive genetic polymorphism. The approval of CYP2D6 genotype testing by the FDA in 2005 has put this enzyme at the cutting-edge of research into personalised medicine. The effects of CYP2D6 genetic polymorphism on tamoxifen metabolism and clinical outcomes in breast cancer patients is currently an important area of translational research. This review article covers recent progress in CYP2D6 pharmacogenomics and its applications to translational medicine.
\end{abstract}

Keywords: Cytochrome P450 2D6, pharmacogenomics, translational medicine.

\section{INTRODUCTION}

The elucidation of the human genome sequence has led to important advances in pharmacogenomics and translational medicine research [1-3]. Genetic factors can account for up to $30 \%$ in differences to drug response between patients [4]. These differences in patient genetic profiles can lead to an alteration in drug effect, with potential risks of drug toxicity or treatment failure [5]. Pharmacogenetics is the study of this interindividual patient variability to drug response and efficacy. Current clinical research is focusing on patient genotype testing and using this genetic information to provide more effective therapeutic targeting in clinical practice [6,7].

The most widely studied group of proteins displaying pharmacogenetic variability are the drug metabolising enzymes and specifically, the cytochrome P450s (CYP). These enzymes are involved in the Phase I metabolism reactions, mainly resulting in drug substrate oxidation. Genetic polymorphism affecting the CYP enzymes can result in altered drug metabolism and efficacy [8]. Cytochrome P450 2D6 (CYP2D6) is one of the most extensively studied metabolic enzymes [9].

\section{MOLECULAR MECHANISM OF CYP2D6}

CYP2D6 functions as a mono-oxygenase enzyme and is predominantly found within the hepatic microsomes. It metabolises up to $30 \%$ of commonly used medications. Important drug classes metabolised by this enzyme include antidepressants, beta-blockers and analgesics. The drug

*Address correspondence to these authors at the Strathclyde Institute of Pharmacy and Biomedical Sciences, University of Strathclyde, Glasgow, Scotland, G4 0NR, UK; Tel: +44(0)141 548 2125; Fax: +44(0)141 552 2562; E-mail: imtiaz.shah@strath.ac.uk substrates are mainly lipophilic bases with a protonated amine group and an aromatic ring [10]. The elucidation of the CYP2D6 crystal structure and the approval of CYP2D6 genotype testing by the FDA in 2005 has put this enzyme at the cutting-edge of translational medicine research $[11,12]$.

The CYP2D6 enzyme is a 479 amino acid protein, which contains a heme group; Protein Data Bank ID: 2f9q [13]. CYP2D6 has a well-defined active site structure, which is located above the heme group. The amino acid residues that have been implicated in substrate recognition and binding are Asp301, Glu216, Phe483 and Phe120; Fig. (1). Both Asp301 and Glu216 play an important role in substrate binding [14]. The Phe 483 and Phe120 residues control the alignment of the substrate molecule within the active site. CYP2D6 main function is drug substrate oxidation, via electron transfer initiated by substrate interaction with the heme-oxygen complex; Fig. (2). The catalytic reaction involves the insertion of one oxygen atom into the substrate molecule and the second oxygen atom is converted into water.

The electron source is provided by NADPH-cytochrome P450 reductase, a flavoenzyme that contains one molecule of each of the coenzymes, flavin adenine dinucleotide (FAD) and flavin mononucleotide (FMN) [15]. The FAD accepts electrons from the NADPH and the reduced species, FADH ${ }^{-}$ transfers the electrons to FMN [16]. The $\mathrm{FMNH}^{-}$then donates the electron to the heme complex, reducing the ferric ion $\left(\mathrm{Fe}^{3+}\right)$ to the ferrous state $\left(\mathrm{Fe}^{2+}\right)$. The CYP reductase binding region is found in the C-terminal region of CYP2D6. This region predominantly contains basic residues that bind to CYP reductase via salt bridges, with Arg-440 being an important binding group [17].

The oxidation reaction is initiated by the activation of an oxygen molecule by the ferrous cation $\left(\mathrm{Fe}^{2+}\right)$. This 


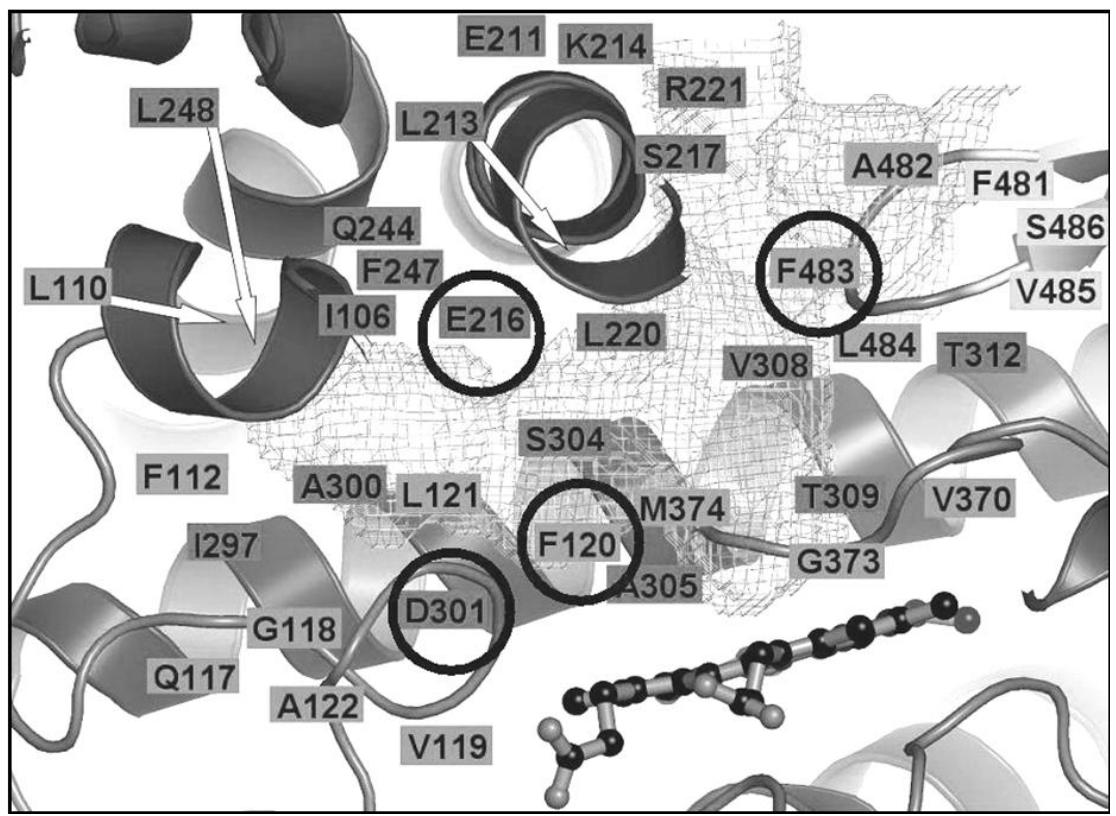

Fig. (1). CYP2D6 active site structure.

D301, E216, F120 and F483 are the important substrate recognition and binding residues. (Copyright: Rowland, P.; et al. J. Biol. Chem., 2006, 281, 7614-22 [13]).

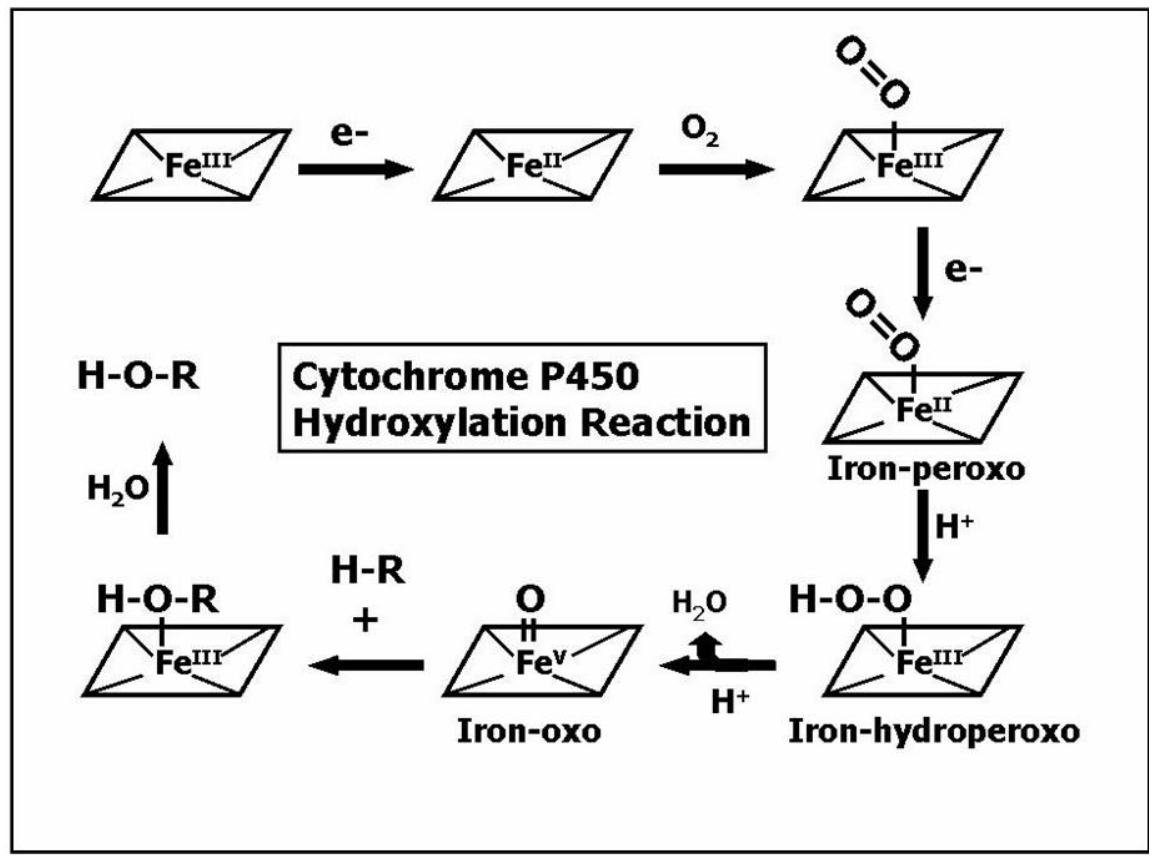

Fig. (2). Cytochrome P450 Catalytic Mechanism.

CYP catalysis involves the insertion of one oxygen atom into the drug substrate molecule $(\mathbf{H}-\mathbf{R})$ and the second oxygen atom is converted into water. The two main reactive iron-oxygen species involved in the catalytic reaction are the electrophilic iron-hydroperoxo and iron-oxo complexes.

hydroxylation reaction occurs at a distance of 5 - $7 \AA$ from the substrate molecule nitrogen atom. This produces an activated iron-oxygen species which reacts with the drug substrates through a variety of mechanisms [18]. The two main reactive iron-oxygen species involved in the catalytic reaction are the electrophilic iron-hydroperoxo and iron-oxo complexes [19]. The iron-hydroperoxo species is formed by protonation of the dioxygen-ferrous complex, iron-peroxo,
Fig. (2). The iron-oxo species results from cleavage of the $\mathrm{O}$ $\mathrm{O}$ bond. The postulated reaction mechanism involves free radical intermediates, although this still remains controversial [20].

\section{GENETIC ASPECTS OF CYP2D6}

CYP2D6 displays extensive genetic polymorphism that influences enzyme expression and function. The gene 
encoding CYP2D6 is located on chromosome 22 (q13.1). Over 100 allelic variants of the CYP2D6 gene have now been identified (CYP2D6 allele nomenclature: www.cypalleles.ki.se/cyp2d6.htm). The enzyme metabolic activity also shows ethnogeographic variation, with differences between Caucasian, Oriental and Afro-Caribbean populations [9].

The three major allelic variants, which are found in the Caucasian population are $C Y P 2 D 6 * 3, C Y P 2 D 6 * 4$ and $C Y P 2 D 6 * 5$ (Table 1). All three variants are associated with poor metaboliser (PM) phenotypes, with $C Y P 2 D 6 * 4$ being the most frequent allele $(20 \%)[9,21]$. The most commonly found allelic variant in the Oriental population is $C Y P 2 D 6 * 10$ allele and this is associated with an intermediate metaboliser (IM) phenotype [22]. This allele results in the production of an unstable enzyme, caused by a double amino acid substitution (Table 1) [23]. The most commonly found allele in the African population is CYP2D6*17 [24]. It is also associated with an IM phenotype, resulting in reduced catalytic activity caused by a triple amino acid substitution (Table 1) [23]. The ultra-rapid metaboliser (UM) phenotype is associated with CYP2D6 gene multiplication and enzyme over-expression. This has been most commonly associated with the Ethiopian and Middle Eastern populations, with up to $30 \%$ allelic frequency $[25,26]$. Due to this extensive genetic polymorphism displayed by $C Y P 2 D 6$, the role of genotype and phenotype testing for this enzyme has become an important area of translational medicine and personalised medicine research [8].

The FDA approved CYP2D6 genotype testing (Amplichip® CYP450) for clinical use in 2005 [27]. The CYP AmpliChip ${ }^{\circledR}$ test involves the identification of a defined genetic mutation in the CYP2D6 and $C Y P 2 C 19$ genes, which results in the expression of a specific drug metabolism phenotype. The genotype test is based on microarray technology, which allows multiple gene expression analysis. The test screens for susceptible patient genotypes and will potentially allow tailoring of drug therapy in an attempt to reduce adverse drug reactions (ADRs) and avoid treatment failure [28]. It classifies patients into the four CYP2D6 phenotypes (PM, IM, EM and UM) by testing for 33 known polymorphisms. Newer microarray technology and PCR methods for CYP genotyping are continuing to be developed [29, 30].

\section{CLINICAL STUDIES OF CYP2D6 PHARMACO- GENETICS}

Clinical studies have shown a potential increased risk of ADRs or treatment failure associated with different $C Y P 2 D 6$ allelic variants [34]. Important drug classes which are metabolised by CYP2D6 and show pharmacogenetic variability are the antidepressants, antipsychotics, analgesics and beta-blockers [28, 34]. Recently, there has been a lot of interest in the effects of CYP2D6 genetic polymorphism on tamoxifen metabolism and clinical outcomes in breast cancer patients $[35,36]$.

Tamoxifen, Fig. (3), is an important drug used in the treatment of breast cancer and metabolised by CYP2D6. Pharmacogenetic variability of this enzyme has been associated with altered tamoxifen treatment response and patient prognosis $[37,38]$. Tamoxifen is metabolised into the more active metabolites, endoxifen and 4-hydroxytamoxifen, Fig. (3) [39]. Both of these metabolites have higher affinity for the oestrogen receptor compared to tamoxifen [40]. The major metabolite of tamoxifen is $N$-desmethyltamoxifen, which is produced via CYP3A4/5. This is then metabolised by CYP2D6 to endoxifen [41]. CYP2D6 also plays a minor role in metabolising tamoxifen to 4-hydroxytamoxifen, which is then metabolised into endoxifen via CYP3A4/5. Patients with CYP2D6 PM/IM phenotype status have been shown to respond less well to tamoxifen treatment due to reduced production of these more active metabolites [42-44]. This has been associated with adverse clinical outcomes in these patients $[37,42]$.

Clinical studies have shown variability in disease progression relating to $C Y P 2 D 6$ genotype status, in breast cancer patients treated with tamoxifen. In Oriental patients,

Table 1. Common Allelic Variants of CYP2D6

\begin{tabular}{|c|c|c|c|}
\hline CYP2D6 Variant Allele & Mutation & Enzyme Activity & References \\
\hline$C Y P 2 D 6 * 3$ & $\begin{array}{l}\text { Frameshift deletion } \\
\text { Non-functional allele }\end{array}$ & $\begin{array}{c}\text { Inactive enzyme (PM) } \\
\text { (1-3\% allelic frequency in Caucasian population) }\end{array}$ & Sachse et al. 1997 [31] \\
\hline$C Y P 2 D 6 * 5$ & $\begin{array}{c}\text { Gene deletion } \\
\text { Non-functional allele }\end{array}$ & $\begin{array}{c}\text { No enzyme (PM) } \\
(\sim 5 \% \text { allelic frequencyin general population })\end{array}$ & $\begin{array}{l}\text { Steen } \text { et al. } 1995[33] \\
\text { Mizutani, } 2003 \text { [21] }\end{array}$ \\
\hline$C Y P 2 D 6 * 10$ & $\begin{array}{c}\text { Double amino acid } \\
\text { substitution } \\
(\mathrm{P} 34 \mathrm{~S}, \mathrm{~S} 486 \mathrm{~T})\end{array}$ & $\begin{array}{l}\text { Reduced activity due to unstable enzyme (IM) } \\
(\sim 50 \% \text { allelic frequency in Oriental population) }\end{array}$ & $\begin{array}{l}\text { Lee } \text { et al. } 2006[22] \\
\text { Shen } \text { et al. } 2007 \text { [23] }\end{array}$ \\
\hline
\end{tabular}


those with the $C Y P 2 D 6 * 10$ genotype have been shown to have poorer clinical outcomes after treatment with tamoxifen. In a Japanese study, patients with the CYP2D6*10 allelic variant had higher breast cancer recurrence rates and shorter disease free periods [37]. Similar results were found in a Chinese population and the study also demonstrated lower concentrations of tamoxifen metabolites in $C Y P 2 D 6 * 10$ genotypes [44]. Clinical studies in Caucasian breast cancer patients have shown that CYP2D6 PMs $(C Y P 2 D 6 * 4$ and $C Y P 2 D 6 * 5$ genotypes) treated with tamoxifen have higher cancer recurrence rates and mortality $[38,45]$. There has therefore been increasing interest in the role $C Y P 2 D 6$ genotype testing for drug treatment selection in breast cancer patients [46].

However, there have been conflicting results as some CYP2D6 genotyping studies have shown no association between allelic variants and tamoxifen efficacy in breast cancer patients [47]. In a recent Japanese study there was found to be no correlation between $C Y P 2 D 6 * 10$ genotype and prognosis in breast cancer patients treated with tamoxifen [48]. Similar results have been also shown for the CYP2D6*4 genotype in a Swedish population [49]. Therefore more rigorous pharmacogenetic clinical studies are required to correlate pharmacokinetic data with clinical response and using larger sample sizes for the different patient phenotypes [50].

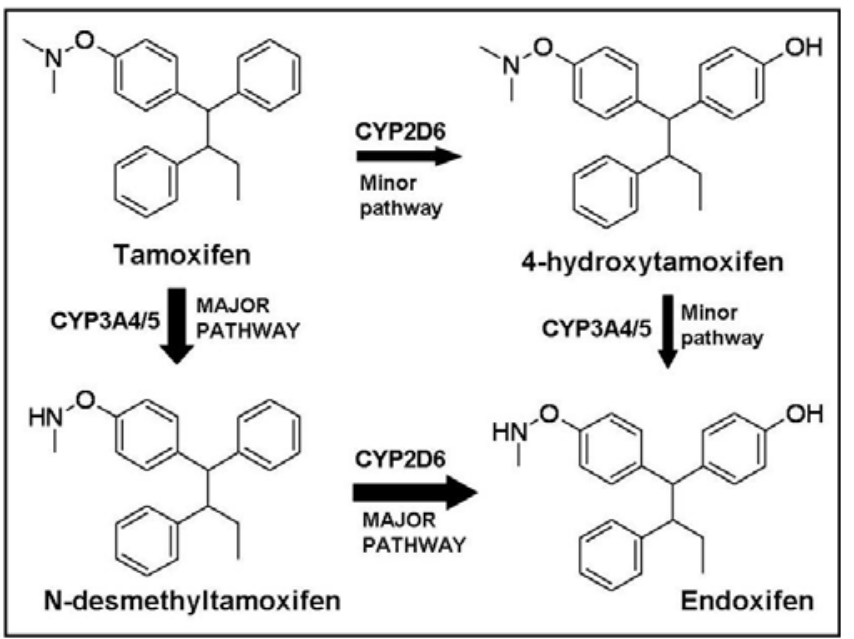

Fig. (3). Tamoxifen Metabolism and CYP2D6.

Tamoxifen is metabolised into the more active metabolites, 4hydroxytamoxifen and endoxifen. The major metabolite of tamoxifen is $\mathrm{N}$-desmethyltamoxifen, which is then metabolised via CYP2D6 to endoxifen. CYP2D6 also directly metabolises tamoxifen into 4-hydroxytamoxifen, which is then metabolised into endoxifen via CYP3A4/5.

Other important drug classes displaying altered clinical response relating to $C Y P 2 D 6$ genotype status are the analgesics and beta-blockers. Tramadol is a commonly used painkiller, which is metabolised by CYP2D6 via $O$ demethylation into the more active metabolite $O$ desmethyltramadol, Fig. (4). A poor analgesic effect has been demonstrated in PM phenotypes treated with tramadol $[51,52]$. On the other hand, UM phenotype patients have displayed an increased incidence of opioid related ADRs (nausea and respiratory depression) [53, 54]. CYP2D6 genotype testing could therefore potentially help in the prevention of ADRs or treatment failure associated with tramadol use [55].

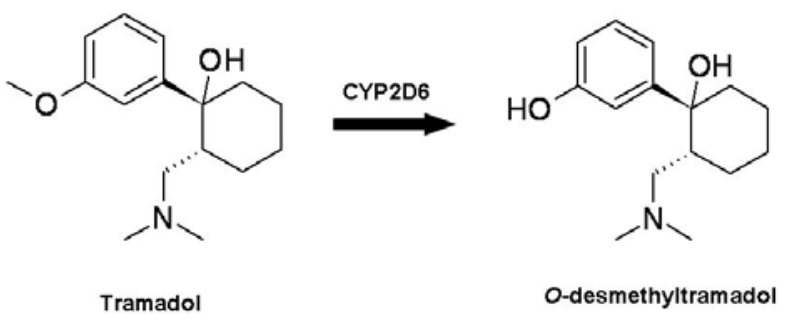

Fig. (4). Tramadol Metabolism and CYP2D6.

Tramadol is metabolised by CYP2D6 via $O$-demethylation into the more active metabolite $O$-desmethyltramadol.

Metoprolol is a $\beta 1$-adrenoceptor antagonist, which is used in the treatment of ischaemic heart disease. Metoprolol is metabolised by CYP2D6 into its inactive metabolites, $\alpha$ hydroxymetoprolol and $O$-desmethylmetoprolol. In experimental studies, CYP2D6 enzyme variants have shown reduced metoprolol metabolism [56]. Clinical studies of CYP2D6 PM phenotypes have demonstrated a potential increased risk of ADRs (hypotension and dizziness) associated with metoprolol treatment [57]. Genotype testing may therefore have a valuable role in beta-blocker therapy selection and further clinical studies are ongoing in this important area of cardiovascular medicine [58].

\section{CONCLUSION}

CYP2D6 pharmacogenomics represents an important area of translational medicine research. The effects of CYP drug metabolism has an important role in the drug discovery process and in lead candidate optimisation (ADME-Tox). CYP pharmacogenetics has also evolved into an important part of drug design and clinical trials [59, 60]. The elucidation of the CYP2D6 crystal structure may have a potential role in computational screening of suitable lead drug candidates [12]. The approval of $C Y P 2 D 6$ genotype testing in clinical practice has been a major advance in personalised medicine research. This may facilitate drug treatment selection and avoidance of adverse drug reactions or treatment failure. The effects of CYP2D6 genetic polymorphism on tamoxifen metabolism and clinical outcomes in breast cancer patients is currently a topical area of translational research.

Despite these important advances in pharmacogenomics, some barriers still remain in translating these research findings into clinical practice. A more rigorous evidencebase for CYP2D6 genotype testing from larger pharmacogenomic clinical trials is required, to help develop standardised clinical guidelines for appropriate use of these tests [50]. Well-developed genomic services are also required for proper implementation of genotype testing and will require considerable education of healthcare professionals, in both the scientific and ethical aspects of pharmacogenomics [61]. With the current financial restrictions to most healthcare budgets, the challenges of funding these services also need to be considered. Results from ongoing clinical studies will provide further information into the cost-effectiveness of the different 
genotype tests and the feasibility of integrating this into clinical practice [62].

\section{ABBREVIATIONS}

$\begin{array}{ll}\text { ADME-Tox }= & \text { Absorption, Distribution, Metabolism, } \\ & \text { Elimination, Toxicology } \\ & =\text { Adverse Drug Reactions } \\ \text { ADR } & \text { Cytochrome P450 } \\ \text { CYP } & =\text { Cytochrome P450 2D6 } \\ \text { CYP2D6 } & =\text { Extensive Metaboliser } \\ \text { EM } & =\text { Flavin adenine dinucleotide } \\ \text { FAD } & =\text { Flavin mononucleotide } \\ \text { FMN } & \text { Intermediate Metaboliser } \\ \text { IM } & =\text { Nicotinamide adenine dinucleotide phospate } \\ \text { NADPH } & =\text { Poor Metaboliser } \\ \text { PM } & =\text { Polymerase Chain Reaction } \\ \text { PCR } & =\text { Ultra-rapid Metaboliser } \\ \text { UM } & \end{array}$

\section{REFERENCES}

[1] International Human Genome Sequencing Consortium. Finishing the euchromatic sequence of the human genome. Nature, 2004, 431, 931-945.

[2] Grant, S.F.; Hakonarson, H. Recent development in pharmacogenomics: from candidate genes to genome-wide association studies. Expert Rev. Mol. Diagn., 2007, 7, 371-393.

[3] Shurin, S.B.; Nabel, E.G. Pharmacogenomics--ready for prime time? N. Engl. J. Med., 2008, 358, 1061-1063.

[4] Evans, W.E.; McLeod, H.L. Pharmacogenomics--drug disposition, drug targets, and side effects. N. Engl. J. Med., 2003, 348, 538-549.

[5] O'shaughnessy, K.M. HapMap, pharmacogenomics, and the goal of personalized prescribing. Br. J. Clin. Pharmacol., 2006, 61, 783786.

[6] Hoffman, E.P. Skipping toward personalized molecular medicine. N. Engl. J. Med., 2007, 357, 2719-2722.

[7] Lesko, L.J. Personalized medicine: elusive dream or imminent reality? Clin, Pharmacol, Ther., 2007, 81, 807-816.

[8] Tomalik-Scharte, D.; Lazar, A.; Fuhr, U.; Kirchheiner, J. The clinical role of genetic polymorphisms in drug-metabolizing enzymes. Pharmacogenomics J., 2008, 8, 4-15.

[9] Ingelman-Sundberg, M. Genetic polymorphisms of cytochrome P450 2D6 (CYP2D6): clinical consequences, evolutionary aspects and functional diversity. Pharmacogenomics J., 2005, 5, 6-13.

[10] Costache, A.D.; Trawick, D.; Bohl, D.; Sem, D.S. AmineDB: large scale docking of amines with CYP2D6 and scoring for druglike properties--towards defining the scope of the chemical defense against foreign amines in humans. Xenobiotica, 2007, 37, 221-245.

[11] Frueh, F.W.; Amur, S.; Mummaneni, P.; Epstein, R.S.; Aubert, R.E.; Deluca, T.M.; Verbrugge, R.R.; Burckart, G.J.; Lesko, L.J. Pharmacogenomic biomarker information in drug labels approved by the United States food and drug administration: prevalence of related drug use. Pharmacotherapy, 2008, 28, 992-998.

[12] Sun, H.; Scott, D.O. Structure-based drug metabolism predictions for drug design. Chem. Biol. Drug Des., 2010, 75, 3-17.

[13] Rowland, P.; Blaney, F.E.; Smyth, M.G.; Jones, J.J.; Leydon, V.R.; Oxbrow, A.K.; Lewis, C.J.; Tennant, M.G.; Modi, S.; Eggleston, D.S.; Chenery, R.J.; Bridges, A.M. Crystal structure of human cytochrome P450 2D6. J. Biol. Chem., 2006, 281, 7614-7622.

[14] Paine, M.J.; McLaughlin, L.A.; Flanagan, J.U.; Kemp, C.A.; Sutcliffe, M.J.; Roberts, G.C.; Wolf, C.R. Residues glutamate 216 and aspartate 301 are key determinants of substrate specificity and product regioselectivity in cytochrome P450 2D6. J. Biol. Chem., 2003, 278, 4021-4027.

[15] Kim, J.J.; Roberts, D.L.; Djordjevic, S.; Wang, M.; Shea, T.M.; Masters, B.S. Crystallization studies of NADPH-cytochrome P450 reductase. Methods Enzymol., 1996, 272, 368-377.
[16] Oprian, D.D.; Coon, M.J. Oxidation-reduction states of FMN and FAD in NADPH-cytochrome P-450 reductase during reduction by NADPH. J. Biol. Chem., 1982, 257, 8935-8944.

[17] Allorge, D.; Breant, D.; Harlow, J.; Chowdry, J.; Lo-Guidice, J.M.; Chevalier, D.; Cauffiez, C.; Lhermitte, M.; Blaney, F.E.; Tucker, G.T.; Broly, F.; Ellis, S.W. Functional analysis of CYP2D6.31 variant: homology modeling suggests possible disruption of redox partner interaction by Arg440His substitution. Proteins, 2005, 59, 339-346.

[18] Guengerich, F.P. Common and uncommon cytochrome P450 reactions related to metabolism and chemical toxicity. Chem. Res. Toxicol., 2001, 14, 611-650.

[19] Schlichting, I.; Berendzen, J.; Chu, K.; Stock, A.M.; Maves, S.A.; Benson, D.E.; Sweet, R.M.; Ringe, D.; Petsko, G.A.; Sligar, S.G. The catalytic pathway of cytochrome p450cam at atomic resolution. Science, 2000, 287, 1615-1622.

[20] Makris, T.M.; von Koenig, K.; Schlichting, I.; Sligar, S.G. The status of high-valent metal oxo complexes in the P450 cytochromes. J. Inorg. Biochem., 2006, 100, 507-518.

[21] Mizutani, T. PM frequencies of major CYPs in asians and caucasians. Drug Metab. Rev., 2003, 35, 99-106.

[22] Lee, S.Y.; Sohn, K.M.; Ryu, J.Y.; Yoon, Y.R.; Shin, J.G.; Kim, J,W. Sequence-based CYP2D6 genotyping in the Korean population. Ther. Drug Monit., 2006, 28, 382-387.

[23] Shen, H.; He, M.M.; Liu, H.; Wrighton, S.A.; Wang, L.; Guo, B. $\mathrm{Li}, \mathrm{C}$. Comparative metabolic capabilities and inhibitory profiles of CYP2D6.1, CYP2D6.10, and CYP2D6.17. Drug Metab. Dispos. 2007, 35, 1292-1300.

[24] Dandara, C.; Masimirembwa, C.M.; Magimba, A.; Sayi, J.; Kaaya, S.; Sommers, D.K.; Snyman, J.R.; Hasler, J.A. Genetic polymorphism of CYP2D6 and CYP2C19 in east- and southern African populations including psychiatric patients. Eur. J. Clin. Pharmacol., 2001, 57, 11-17.

[25] Aklillu, E.; Persson, I.; Bertilsson, L.; Johansson, I.; Rodrigues, F. Ingelman-Sundberg, M. Frequent distribution of ultrarapid metabolizers of debrisoquine in an ethiopian population carrying duplicated and multiduplicated functional CYP2D6 alleles. $J$. Pharmacol. Exp. Ther., 1996, 278, 441-446.

[26] McLellan, R.A.; Oscarson, M.; Seidegard, J.; Evans, D.A.; Ingelman-Sundberg, M. Frequent occurrence of CYP2D6 gene duplication in Saudi Arabians. Pharmacogenetics, 1997, 7, 187191.

[27] de Leon, J.; Susce, M.T.; Murray-Carmichael, E. The AmpliChiptrade mark CYP450 Genotyping Test: Integrating a New Clinical Tool. Mol. Diagn. Ther., 2006, 10, 135-151.

[28] de Leon, J.; Armstrong, S.C.; Cozza, K.L. Clinical guidelines for psychiatrists for the use of pharmacogenetic testing for CYP450 2D6 and CYP450 2C19. Psychosomatics, 2006, 47, 75-85.

[29] Deeken, J. The Affymetrix DMET platform and pharmacogenetics in drug development. Curr. Opin. Mol. Ther., 2009, 11, 260-268.

[30] Sukumaran, S.M.; Potsaid, B.; Lee, M.Y.; Clark, D.S.; Dordick, J.S. Development of a fluorescence-based, ultra high-throughput screening platform for nanoliter-scale cytochrome p450 microarrays. J. Biomol. Screen., 2009, 14, 668-678.

[31] Sachse, C.; Brockmoller, J.; Bauer, S.; Roots, I. Cytochrome P450 2D6 variants in a Caucasian population: allele frequencies and phenotypic consequences. Am. J. Hum. Genet., 1997, 60, 284-295.

[32] Marez, D.; Legrand, M.; Sabbagh, N.; Guidice, J.M.; Spire, C.; Lafitte, J.J.; Meyer, U.A.; Broly, F. Polymorphism of the cytochrome P450 CYP2D6 gene in a European population: characterization of 48 mutations and 53 alleles, their frequencies and evolution. Pharmacogenetics, 1997, 7, 193-202.

[33] Steen, V.M.; Molven, A.; Aarskog, N.K.; Gulbrandsen, A.K. Homologous unequal cross-over involving a $2.8 \mathrm{~kb}$ direct repeat as a mechanism for the generation of allelic variants of human cytochrome P450 CYP2D6 gene. Hum. Mol. Genet., 1995, 4, 22512257

[34] Zhou, S.F. Polymorphism of human cytochrome P450 2D6 and its clinical significance: part II. Clin. Pharmacokinet., 2009, 48, 761804.

[35] Goetz, M.P.; Kamal, A.; Ames, M.M. Tamoxifen pharmacogenomics: the role of CYP2D6 as a predictor of drug response. Clin. Pharmacol. Ther., 2008, 83, 160-166.

[36] Schroth, W.; Goetz, M.P.; Hamann, U.; Fasching, P.A.; Schmidt, M.; Winter, S.; Fritz, P.; Simon, W.; Suman, V.J.; Ames, M.M.; Safgren, S.L.; Kuffel, M.J.; Ulmer, H.U.; Bolander, J.; Strick, R.; 
Beckmann, M.W.; Koelbl, H,; Weinshilboum, R.M.; Ingle, J.N.; Eichelbaum, M.; Schwab, M.; Brauch, H. Association between CYP2D6 polymorphisms and outcomes among women with early stage breast cancer treated with tamoxifen. JAMA, 2009, 302, 1429-1436.

[37] Kiyotani, K.; Mushiroda, T.; Sasa, M.; Bando, Y.; Sumitomo, I.; Hosono, N.; Kubo, M.; Nakamura, Y.; Zembutsu, H. Impact of CYP2D6*10 on recurrence-free survival in breast cancer patients receiving adjuvant tamoxifen therapy. Cancer Sci., 2008, 99, 995999.

[38] Schroth, W.; Antoniadou, L.; Fritz, P.; Schwab, M.; Muerdter, T.; Zanger, U.M.; Simon, W.; Eichelbaum, M.; Brauch, H. Breast cancer treatment outcome with adjuvant tamoxifen relative to patient CYP2D6 and CYP2C19 genotypes. J. Clin. Oncol., 2007, 25, 5187-5193.

[39] Ingle, J.N. Pharmacogenomics of tamoxifen and aromatase inhibitors. Cancer, 2007, 112, 695-699.

[40] Lim, Y.C.; Desta, Z.; Flockhart, D.A.; Skaar, T.C. Endoxifen (4hydroxy-N-desmethyl-tamoxifen) has anti-estrogenic effects in breast cancer cells with potency similar to 4-hydroxy-tamoxifen. Cancer Chemother. Pharmacol., 2005, 55, 471-478.

[41] Desta, Z.; Ward, B.A.; Soukhova, N.V.; Flockhart, D.A. Comprehensive evaluation of tamoxifen sequential biotransformation by the human cytochrome P450 system in vitro: prominent roles for CYP3A and CYP2D6. J. Pharmacol. Exp. Ther., 2004, 310, 1062-1075.

[42] Goetz, M.P.; Knox, S.K.; Suman, V.J.; Rae, J.M.; Safgren, S.L.; Ames, M.M.; Visscher, D.W.; Reynolds, C.; Couch, F.J.; Lingle, W.L.; Weinshilboum, R.M.; Fritcher, E,G.; Nibbe, A.M.; Desta, Z.; Nguyen, A.; Flockhart, D.A.; Perez, E.A.; Ingle, J.N. The impact of cytochrome P450 2D6 metabolism in women receiving adjuvant tamoxifen. Breast Cancer Res. Treat., 2007, 101, 113-121.

[43] Lim, H.S.; Ju, L.H.; Seok, L.K.; Sook, L.E.; Jang, I.J.; Ro, J. Clinical implications of CYP2D6 genotypes predictive of tamoxifen pharmacokinetics in metastatic breast cancer. J. Clin. Oncol., 2007, 25, 3837-3845.

[44] Xu, Y.; Sun, Y.; Yao, L.; Shi, L.; Wu, Y.; Ouyang, T.; Li. J.; Wang, T.; Fan, Z.; Fan, T.; Lin, B.; He, L.; Li, P.; Xie, Y. Association between CYP2D6 $* 10$ genotype and survival of breast cancer patients receiving tamoxifen treatment. Ann. Oncol., 2008, 19, 1423-1429.

[45] Bijl, M.J.; van Schaik, R.H.; Lammers, L.A.; Hofman, A.; Vulto, A.G.; van, G.T.; Stricker, B.H.; Visser, L.E. The CYP2D6*4 polymorphism affects breast cancer survival in tamoxifen users. Breast Cancer Res. Treat., 2009, 118, 125-30.

[46] Hartman, A.R.; Helft, P. The ethics of CYP2D6 testing for patients considering tamoxifen. Breast Cancer Res., 2007, 9, 103.

[47] Nowell, S.A.; Ahn, J.; Rae, J.M.; Scheys, J.O.; Trovato, A.; Sweeney, C.; MacLeod, S.L.; Kadlubar, F.F.; Ambrosone, C.B. Association of genetic variation in tamoxifen-metabolizing enzymes with overall survival and recurrence of disease in breast cancer patients. Breast Cancer Res. Treat., 2005, 91, 249-258.

[48] Okishiro, M.; Taguchi, T.; Jin, K.S.; Shimazu, K.; Tamaki, Y.; Noguchi, S. Genetic polymorphisms of CYP2D6 10 and CYP2C19
2, 3 are not associated with prognosis, endometrial thickness, or bone mineral density in Japanese breast cancer patients treated with adjuvant tamoxifen. Cancer, 2009, 115, 952-961.

[49] Wegman, P.; Elingarami, S.; Carstensen, J.; Stal, O.; Nordenskjold, B.; Wingren, S. Genetic variants of CYP3A5, CYP2D6, SULT1A1, UGT2B15 and tamoxifen response in postmenopausal patients with breast cancer. Breast Cancer Res., 2007, 9, R7.

[50] Limdi, N.A.; Veenstra, D.L. Expectations, validity, and reality in pharmacogenetics. J. Clin. Epidemiol., 2010, 63, 960-969.

[51] Halling, J.; Weihe, P.; Brosen, K. CYP2D6 polymorphism in relation to tramadol metabolism: a study of faroese patients. Ther. Drug Monit., 2008, 30, 271-275.

[52] Stamer, U.M.; Musshoff, F.; Kobilay, M.; Madea, B.; Hoeft, A.; Stuber, F. Concentrations of tramadol and O-desmethyltramadol enantiomers in different CYP2D6 genotypes. Clin. Pharmacol. Ther., 2007, 82, 41-47.

[53] Kirchheiner, J.; Keulen, J.T.; Bauer, S.; Roots, I.; Brockmoller, J. Effects of the CYP2D6 gene duplication on the pharmacokinetics and pharmacodynamics of tramadol. J. Clin. Psychopharmacol., 2008, 28, 78-83.

[54] Stamer, U.M.; Stuber, F.; Muders, T.; Musshoff, F. Respiratory depression with tramadol in a patient with renal impairment and CYP2D6 gene duplication. Anesth. Analg., 2008, 107, 926-929.

[55] Foster, A.; Mobley, E.; Wang, Z. Complicated pain management in a CYP450 2D6 poor metabolizer. Pain Pract., 2007, 7, 352-356.

[56] Bapiro, T.E.; Hasler, J.A.; Ridderstrom, M.; Masimirembwa, C.M. The molecular and enzyme kinetic basis for the diminished activity of the cytochrome P450 2D6.17 (CYP2D6.17) variant. Potential implications for CYP2D6 phenotyping studies and the clinical use of CYP2D6 substrate drugs in some African populations. Biochem. Pharmacol., 2002, 64, 1387-1398.

[57] Wuttke, H.; Rau, T.; Heide, R.; Bergmann, K.; Bohm, M.; Weil, J.; Werner, D.; Eschenhagen, T. Increased frequency of cytochrome P450 2D6 poor metabolizers among patients with metoprololassociated adverse effects. Clin. Pharmacol. Ther., 2002, 72, 429437.

[58] Shin, J.; Johnson, J.A. Pharmacogenetics of beta-blockers. Pharmacotherapy, 2007, 27, 874-887.

[59] Brockmoller, J.; Tzvetkov, M.V. Pharmacogenetics: data, concepts and tools to improve drug discovery and drug treatment. Eur. J. Clin. Pharmacol., 2008, 64, 133-157.

[60] Roses, A.D. Pharmacogenetics in drug discovery and development: a translational perspective. Nat. Rev. Drug Discov., 2008, 7, 807817.

[61] Ormond, K.E.; Wheeler, M.T.; Hudgins, L.; Klein, T.E.; Butte, A.J.; Altman, R.B.; Ashley, E.A.; Greely, H.T. Challenges in the clinical application of whole-genome sequencing. Lancet, 2010, 375, 1749-1751.

[62] Frueh, FW. Real-world clinical effectiveness, regulatory transparency and payer coverage: three ingredients for translating pharmacogenomics into clinical practice. Pharmacogenomics, 2010, 11, 657-660.

(C) Shah et al.; Licensee Bentham Open.

This is an open access article licensed under the terms of the Creative Commons Attribution Non-Commercial License (http://creativecommons.org/licenses/by-nc/3.0/) which permits unrestricted, non-commercial use, distribution and reproduction in any medium, provided the work is properly cited. 